\title{
LEGISLATIVE BARGAINING UNDER WEIGHTED VOTING ${ }^{1}$
}

\author{
James M. Snyder, Jr. \\ Department of Political Science and Department of Economics \\ Massachusetts Institute of Technology \\ Michael M. Ting \\ Department of Political Science \\ University of North Carolina at Chapel Hill \\ Stephen Ansolabehere \\ Department of Political Science \\ Massachusetts Institute of Technology
}

September, 2001

${ }^{1}$ James Snyder and Michael Ting gratefully acknowledge the financial support of National Science Foundation Grant SES-0079035. 


\begin{abstract}
Voting institutions commonly assign different weights across voters. Most analyses of such systems assume that the relative influence of each player is non-linear in her voting weight. We reassess this assumption with a distributive bargaining game that closely resembles the closed-rule, infinite-horizon Baron-Ferejohn (1989) model. In equilibrium, voters with lower weights are typically perfect substitutes for voters with higher weights. Hence, each voter's power is exactly proportional to her voting weight. An exception occurs when sufficient numbers of high-weight voters exist. In this case, low-weight voters are relatively more powerful than high-weight voters because their probabilities of being recognized to make a proposal are equal to those of high-weight voters. These results call into question the applicability of power indices such as the Banzhaf index and Shapley-Shubik value, which are often convex in voting weights.
\end{abstract}




\section{Introduction}

Collective decision-making frequently involves situations in which actors have different numbers of votes. Some institutions use explicit weighted voting rules that assign unequal numbers of votes or weights to different members. Examples include the European Union Council of Ministers, the U.S. Electoral College, the International Monetary Fund, the International Energy Agency, and the International Coffee Council. Choice of weights is a subject of on-going controversy in such bodies. In other institutions, blocs of votes are assembled and cast together. Important examples are shareholder voting in corporations and voting in legislatures with unified parties or factions. How does the distribution of votes affect who gets what?

Elementary microeconomic theory teaches that in competitive situations perfect substitutes have the same price. In a political setting in which votes might be traded or transferred in the formation of coalitions, one might expect the same logic to apply. If a legislator or bloc has $k$ votes, that legislator or bloc should command a price for those votes equal to the total price of $k$ players that each have 1 vote. Put in terms of expected payoffs, then, the player with $k$ votes should expect to have a payoff $k$ times as great as the payoff expected by a player with 1 vote. If "expected payoff" can be used as a measure of "power," then the player with $k$ votes should also expect to have $k$ times as much power as the player with 1 vote. $^{1}$

In this paper, we present a straightforward model of divide-the-dollar politics that captures this intuition. We show that the non-cooperative bargaining model of Baron and Ferejohn (1989) leads naturally to the result that expected payoffs are proportional to voting weights. $^{2}$

\footnotetext{
${ }^{1}$ Theorists working on this problem commonly equate power and expected payoffs. There is some debate over whether the definition of power should also include the ability to change the outcome, even though the action does not result in an increase in, and may even lower, the payoff for the pivotal actor. See Felsenthal and Machover (1998) for a discussion of the issues, especially the distinction between "I-power" and "P-power". In this paper we use the terms power and expected payoffs interchangeably.

${ }^{2}$ This is the most widely used model of legislative bargaining, and has been used extensively to study various aspects of distributive politics and government institutions. See Harrington (1989, 1990a, 1990b), Baron (1991, 1996, 1998), Baron and Kalai (1993), Calvert and Dietz (1996), Winter (1996), Diermeier and Feddersen (1998), Banks and Duggan (2000), LeBlanc, Snyder and Tripathi (2000), McCarty (2000a, 2000b),
} 
There are two types of equilibria. The first type is an "interior" equilibrium in which each player's expected payoff is equal to his share of the total voting weight. The second type is a "corner" equilibrium in which players with the largest weights have expected payoffs that are proportional to their voting weights but their shares are less than their share of the weight (so the factor of proportionality is less than one), and players with the smallest weights all receive expected payoffs greater than their shares of the total voting weight. Which type of equilibrium occurs depends on the distribution of voting weights.

The intuition is straightforward, and follows from a simple substitution argument. In the Baron-Ferejohn model, a randomly drawn legislator makes a proposal-a division of the dollar - which is then put to a vote. Proposers seeks to offer as little of the dollar as possible to others, because they keep the residual for themselves. Suppose type-1 players have a continuation value of 2 and a voting weight of 1 , while type-2 players have a continuation value of 5 and a voting weight of 2 . Then rational proposers seeking to minimize the costs of the coalitions they construct will never include type-2 players in their coalitions (except, perhaps, because of "integer" issues). Proposers will substitute type-1 players for type-2 players whenever possible, since two type-1 players have the same total voting weight as one type-2 player, but a total cost that is $4 / 5$ as much.

At a "corner" equilibrium the players can be divided into two distinct groups, defined by some cutoff weight $t_{0}$. Players with voting weights less than $t_{0}$ have expected payoffs that are greater than their shares of the total voting weights, while players with voting weights greater than (or equal to) $t_{0}$ have expected payoffs that are less than their shares of the total voting weight. All players with voting weights greater than (or equal to) $t_{0}$ have expected payoffs that are equal to some $\theta$ times their voting weight, with $\theta<1$. The reason weak players have expected payoffs that are greater than their shares of the voting weight is their proposal power. By assumption, this is assigned equally to all players. The corner equilibria occur when the weakest players are so weak that, even if no other proposers ever include them as coalition partners, their proposal power alone is enough to yield an expected payoff Norman (2000), and Eraslan (2001). 
greater than their share of the voting weight.

Most theoretical and applied analyses of weighted voting employ power indices, such as the Shapley-Shubik value, the Banzhaf index, and the Deegan-Packel index. ${ }^{3}$ These indices do not have the feature that perfect substitutes have the same price or expected value. Rather, these indices are generally highly nonlinear in the voting weights. Many scholars see this as quite natural. One example is Lucas:

It is fallacious to expect that one's voting power is directly proportional to the number of votes he can deliver. Yet many attempts to correct inequalities merely assign weights to a delegate proportional to the number of inhabitants he represents, and it is felt that this preserves some equality at the level of the individual citizens. Paradoxically, those who advocate that they are the main beneficiaries of the weighted systems such as the Electoral College are very often the ones most hurt by it in terms of power indices... Power is not a trivial function of one's strength as measured by his number of votes. Simple additive or division arguments are not sufficient, but more complicated relations are necessary to understand the real distribution of influence (Lucas, 1978, page 184).

Another example is Brams and Affuso:

...a measure like Banzhaf's is not only an eminently reasonable indicator of a crucial aspect of voting power - the ability of a member to change an outcome by changing its vote - but also highlights the fact that size (as reflected by voting weights) and voting power may bear little relationship to each other (Brams and Affuso, 1985, page 138).

The standard power indices are justified in terms of cooperative game theory or axiomatic approaches. They are based on the idea that all orderings, or winning coalitions, or minimalwinning coalitions, are equally likely to form, regardless of how expensive or cheap they are. In contrast, under the competitive bargaining logic expensive coalitions will form rarely or not at all, and cheap coalitions will form quite often.

The competitive bargaining logic produces several key predictions that differ from power indices. First, as noted, at an interior equilibrium the expected payoffs of players depend linearly on the number of votes. Second, in the corner equilibria, it is the weaker players

\footnotetext{
${ }^{3}$ See Shapley (1953), Shapley and Shubik (1954), Banzhaf (1965), and Deegan and Packel (1978) for definitions of these indices.
} 
that receive expected payoffs greater than their weight. By contrast, power indices typically assign disproportionate power to players with higher voting weights. Third, even "dummy" players can have positive expected payoffs, because all players have some chance of being chosen as proposer. By contrast, power indices assign zero power to any player with too few votes to be pivotal in at least one coalition. We view these as testable predictions, and leave that for further work.

Our results have important implications for the empirical and normative literature on weighted voting. An extensive literature examines weighted voting and bloc voting in parliaments, economic organizations such as the IMF and International Coffee Cartel, the U.S. Electoral College, and other institutions. Most of this literature uses power indices, especially the Shapley-Shubik and Banzhaf indices, to critique various schemes for the distribution of votes within organizations. ${ }^{4}$ These arguments have even been used in court cases to justify various voting schemes (though with limited success). We will discuss the implications of our results for the Council of Ministers of the European Union, which has been an important subject of continued controversy because of the EU is of growing importance and because periodic expansions of the EU require new distributions of voting weights. ${ }^{5}$ If our results are right, then voting weights proportional to populations would produce equitable distributions of payoffs in expectation.

Beyond these applications, our paper represents an important extension of the theoretical work using the Baron-Ferejohn legislative bargaining model. Our paper is most closely related to Winter (1996) and McCarty (2000a), who study variants of the Baron-Ferejohn model with veto players, and to McCarty (2000b) who studies a variant that incorporates an executive veto. To our knowledge, no previous papers have used the Baron-Ferejohn model - or any non-cooperative model that incorporates endogenous proposals and majority

\footnotetext{
${ }^{4}$ See, for example, Banzhaf (1968), Owen (1975), Merrill (1978), Dreyer and Schotter (1980), Holler (1982), Bates and Lien (1985), Rabinowitz and MacDonald (1986), Rapoport and Golan (1985), Strom, Budge, and Laver (1994), Konig and Brauninger (1996), and Calvo and Lasaga (1997).

${ }^{5}$ See Brams and Affuso (1985), Hosli (1993), Widgren (1994), Lane and Maeland (1995), Lane, Maeland, and Berg (1995), Teasdale (1996), Felsenthal and Machover (1997, 2001, n.d.), Laruelle and Widgren (1998), Konig and Brauninger (1998), Holler and Widgren (1999), Garrett and Tsebelis (1999a, 1999b, 2001), Sutter (2000a, 2000b), Tsebelis and Garrett (2000), and Widgren (2000).
} 
rule - to study weighted voting. ${ }^{6}$

\section{Model and Results}

\subsection{The Model}

In the model, the players are a continuum of legislators distributed uniformly on $\mathbf{L} \equiv$ $[0, n)$, where $n$ is a positive integer. Legislators each belong to one of $T$ types, defined by their voting weights, where $1 \leq T \leq n$. A type $t$ legislator has a voting weight $w_{t}$ and belongs to the interval $L_{t} \subseteq \mathbf{L}$, where $\mathbf{L}=\cup_{t=1}^{T} L_{t}$. We assume that weights are positive integers and that $w_{i}<w_{j}$ for any $i<j$, with $w_{1}=1$. For convenience, we also assume that each $L_{t}$ is arranged in "increasing" order, so that legislators in $[0,1)$ belong to $L_{1}$ (with weight 1 ) and legislators in $\left[n-1, n\right.$ ) belong to $L_{T}$ (with weight $w_{T}$ ). Each type $t$ is subdivided into $n_{t}$ non-intersecting intervals or blocs of length 1 , where $\sum_{t=1}^{T} n_{t}=n$. Denote bloc $j$ of type $t L_{t j}$, so that $L_{t}=\cup_{j=1}^{n_{t}} L_{t j}$.

The legislature works via a generalized majority rule. For any coalition of legislators $\mathbf{C} \subseteq \mathbf{L}$, let $l_{t}(\mathbf{C})$ represent the measure of type $t$ legislators contained within (i.e., the length of $\left.\mathbf{C} \cap L_{t}\right)$. Let $w(\mathbf{C})=\sum_{t=1}^{T} l_{t}(\mathbf{C}) w_{t}$ represent its total voting weight, and $w=w(\mathbf{L})=$ $\sum_{t=1}^{T} n_{t} w_{t}$ the combined weight of all legislators. A coalition $\mathbf{C}$ is winning if and only if $w(\mathbf{C}) \geq \underline{w}$, where $\underline{w} \geq \frac{w}{2}$. We denote by $\mathcal{W}$ the set of winning coalitions.

This formalization of the legislature, while somewhat artificial, avoids a number of integer problems. For example, if the set of legislators is discrete and there are at least two types of legislators, it is possible for optimal minimum winning coalitions to be of different sizes. With a continuum of legislators, no coalition builder will ever want a coalition with weight greater than $\underline{w}$. As the examples in Section 3 suggest, this setup does not affect the results substantially. ${ }^{7}$

\footnotetext{
${ }^{6}$ Other non-cooperative models of n-person bargaining include Selten (1981), Binmore (1987), Gul (1989), Chatterjee, Dutta, Ray, and Sengupta (1993), and Moldovanu and Winter (1995), Hart and Mas Colell (1996), and Okada (1996). To our knowledge, none of these has been applied to the study of legislative politics. Merlo and Wilson (1995) study distributive politics under unanimity rule. Finally, other cooperative solution concepts applied to weighted voting games include bargaining sets, bargaining aspirations, the kernel, and the competitive solution. See, for example, Schofield (1976, 1978, 1982, 1987), McKelvey, Ordeshook and Winer (1978), Bennett (1983a, 1983b), and Holler (1987).

${ }^{7}$ We hope that this simplification proves useful for fut ure work on distributive politics in legislatures.
} 
We consider the closed-rule, divide-the-dollar game studied by Baron and Ferejohn (1989). In each period, the moves are as follows. Nature randomly draws a proposer from the set of legislators. This draw is uniform on $\mathbf{L}$ and i.i.d. across periods, so that the probability of the proposer belonging to any given bloc is always $1 / n$. The proposer proposes a division of the dollar, subject to the constraint that all members in the proposer's bloc receive the same payoff as herself. "The proposer can thus be thought of as the bloc's "spokesperson" or "representative." All legislators then vote for or against the proposal. If the proposal receives weight $\underline{w}$ in support, then the dollar is divided and the game ends. If the proposal is rejected, then a new proposer is randomly drawn and the game continues. We look at the infinite-horizon game, with no discounting. The game can be treated as a sequence of identical subgames, where each subgame begins with nature's move to draw a proposer. To conserve on notation, we omit reference to time periods except where necessary.

In each period, the strategy for a proposer in bloc $j$ of type $t$ can be represented as follows:

$$
X_{t j}:\left\{f \mid f: \mathbf{L} \rightarrow \Re^{+}, \int_{\mathbf{L}} f(z) \mathrm{d} z \leq 1, f(z)=k \text { for all } z \in L_{t j}\right\},
$$

where $z$ represents the position of a generic legislator and $k \geq 0$ is the payment offered to all members of the proposer's bloc. Each legislator's voting strategy is then simply a function mapping the offered amount to a probability of voting:

$$
\phi: \Re^{+} \rightarrow \Delta(\{0,1\})
$$

We impose two standard tie-breaking rules. First, legislators who are indifferent between the offered proposal and continuing to the next period vote for the proposal. ${ }^{9}$ Second, legislators vote as if they were pivotal. Because of the continuum of legislators, a measure zero set of legislators cannot affect the outcome, but voting 'non-pivotally' is clearly weakly dominated for any individual legislator, and strictly so for any set of legislators of positive measure.

\subsection{Results}

\footnotetext{
${ }^{8}$ Since each bloc consists of only legislators of a single type, only the proposer's bloc, and not her exact location, is relevant. We make this assumption so that each legislator's "recognition probability" is positive. Otherwise, the continuation payoff of each legislator will be 0 .

${ }^{9}$ It is straightforward to verify that assuming otherwise would make the proposer's maximization problem not well defined.
} 
We look for symmetric, stationary, subgame perfect equilibria (SSSPE's). Symmetry means that all players of the same type are treated symmetrically (although different types may be treated differently). Stationarity means that each player uses history-independent strategies at all proposal-making stages, and voting strategies that only depend on the current proposal. SSSPE's will have the following properties. By symmetry, for each type $t$, the continuation value of all type-t players at the beginning of each subgame will be equal. By stationarity, these values will also be the same for each subgame. Let $v_{t}$ be the continuation value of type- $t$ players at the beginning of each subgame.

These restrictions allow us to narrow the set of proposals that may occur in equilibrium. At an SSSPE, the proposer must offer at least $v_{t}$ to a type- $t$ player in order to obtain that player's support. Since proposers wish to minimize their offers, every legislator (other than those in the proposer's bloc) must be offered either $v_{t}$ or 0 in equilibrium. For each coalition $\mathbf{C}$, let $v(\mathbf{C})=\sum_{t=1}^{T} v_{t} l_{t}(\mathbf{C})$ be the total "cost" of $\mathbf{C}$. For a proposer in bloc $L_{t j}$, let $\underline{v}_{t}=\min _{\left\{\mathbf{C} \mid L_{t j} \subseteq \mathbf{C}, \mathbf{C} \in \mathcal{W}\right\}} v\left(\mathbf{C} \backslash L_{t j}\right)$ be the minimum total payment proposed to coalition partners outside of $L_{t j}$. All legislators in $L_{t j}$ then receive $1-\underline{v}_{t}$. Also, let $q_{t}$ be the average probability that a legislator in $L_{t j}$ is chosen as a coalition partner, given that someone outside of $L_{t j}$ is the proposer. ${ }^{10}$ Then,

$$
v_{t}=\frac{1}{n}\left(1-\underline{v}_{t}\right)+\frac{n-1}{n} q_{t} v_{t}
$$

Or,

$$
v_{t}=\frac{1-\underline{v}_{t}}{n-(n-1) q_{t}}
$$

The following proposition characterizes the SSSPE's for the "interior" case. In any equilibrium the expected payoff (continuation value) of each legislator is proportional to his voting weight.

Proposition 1. Suppose $w \leq \underline{w}+n-1$. Then at any SSSPE, $v_{t}=w_{t} / w$ for all $t$.

Proof. See Appendix.

In the equilibrium of Proposition $1, \underline{v}_{t}=\underline{w} / w-v_{t}=\left(\underline{w}-w_{t}\right) / w$ for all $t$, so we can solve

\footnotetext{
${ }^{10}$ Note that $v_{t}$ and $q_{t}$ do not depend on $j$, since by symmetry they are identical across blocs within $L_{t}$.
} 
equation (1) for $q_{t}$ to obtain

$$
q_{t}=1-\frac{w-\underline{w}}{(n-1) w_{t}}
$$

Clearly, $q_{t}$ is strictly increasing in $w_{t}$. Thus, the main reason types with higher voting weights receive higher expected payoffs in equilibrium is that proposers are more likely to choose them as coalition partners. Note also that in the case of simple majority rule $(\underline{w}=w / 2)$, the condition in Proposition 1 becomes $w \leq 2(n-1)$.

The next proposition characterizes the SSSPE in the "corner" case. In this case, the types with the smallest voting weights have expected payoffs greater than their relative weight, while those with the largest weights receive expected payoffs lower than their relative weight. Also, for all types $t \geq t_{0}$, expected payoffs are proportional to voting weights.

Proposition 2. Suppose $w>\underline{w}+n-1$. Then all SSSPE have the following properties: (i) there is a type $t_{0}>1$ and a number $\theta<1$ such that $v_{t}=\theta w_{t} / w$ for all $t \geq t_{0}$ and $v_{t}>w_{t} / w$ for all $t<t_{0}$, and (ii) $q_{t}=0$ for all $t<t_{0}$.

Proof. See Appendix.

These equilibria might or might not be "unique," depending on the distribution of voting weights. For some configurations there is a unique type of equilibrium - that is, a unique cutoff value $t_{0}$. For other configurations there are several types of equilibria, each associated with a different cutoff values.

\subsection{Discussion}

In a corner equilibrium, the high-voting-weight type are "underpaid" relative to their voting weight, while it is the low-weight types that are "overpaid." This is the opposite of what tends to happen for many of the power indices.

The intuition behind this result is that equal proposal probabilities disproportionately benefit voters with low weights. A corner equilibrium occurs when the expected payoff to some low-weight voter is greater than his share of the weight, even when no other proposers ever choose him as a coalition partner. The high payoff that occurs in the event that he (or someone in his bloc) is proposer determines his entire expected payoff. This suggests that if recognition probabilities were adjusted to reflect voting weights, linearity in expected payoffs 
and voting weights would be restored. The following result establishes the existence of such equilibria.

Remark. Suppose $w>\underline{w}+n-1$ and the recognition probability of each type $t$ voter is $w_{t} / w$. Then there exists an SSSPE such that $v_{t}=w_{t} / w$ for all $t$.

Proof. See Appendix.

We therefore expect that payoffs proportional to voting weights will be more likely when recognition probabilities follow the same pattern as voting weights.

Note also that corner equilibria are more likely to occur when the threshold for victory $\underline{w}$ is low, since lower values of $\underline{w}$ imply greater benefits to being proposer. Thus, we expect linear payoffs when $\underline{w}$ is high, that is, when the collective choice rule is supermajoritarian. An open rule also makes proposing less valuable, since the proposer must offer higher payoffs to his coalition partners and must often build supermajorities to reduce the probability of counter-proposals (see Baron and Ferejohn, 1989). Thus, we also expect that linear payoffs will be more likely under an open rule.

Finally, the following comparative statics results follow immediately. Except for types that "corner", a small increase in voting weight always increases a player's expected payoff, but a small increase in proposal probability does not. For the types that corner (these are the types with low voting weight), a small increase in voting weight carries no benefit (since these types will still "never" be included in a coalition), but a small increase in proposal probability increases the expected payoff.

\section{Examples of Finite Legislatures}

The propositions above apply to infinitely large legislatures. However, as the following examples show, the basic logic underlying the propositions holds for finite legislatures as well, even legislatures with few players.

Before proceeding with the examples, we must consider the matter of voting weights. In the continuum case studied in section 2 , each weighted voting game has a unique representation (up to a set of measure zero). If we change the weights of any set of players with positive measure, then we change the set of winning coalitions, producing a different game. 
Each finite weighted voting game, however, can be represented by many different vectors of weights - that is, there are different vectors of weights that produce the exact same set of winning coalitions. Which weights should we choose to characterize a given finite weighted voting game?

A weighted voting game is homogeneous if all minimal winning coalitions have exactly the same total voting weight. Isbell (1956) shows that if a game has a homogeneous representation, then this representation is unique, and the voting weights are minimum integer weights. Note that in the continuum formulation in section 2 , the weights are homogeneous.

Table 1 compares the Shapley-Shubik index, Banzhaf index, and expected payoffs under the competitive bargaining game, for all strong four-, five-, and six-player weighted voting games. ${ }^{11}$ We present each game in terms of its minimum integer weights. We calculated the unique expected payoffs supportable by SSSPE's to all of these games. ${ }^{12}$ We also computed the Shapley-Shubik and Banzhaf power indices for these games.

Based on the results in the table, we make the following conjectures for finite games: For homogeneous games that satisfy the conditions of proposition 1, expected payoffs will be linear in the homogeneous weights. For homogeneous games that satisfy the conditions of proposition 2, expected payoffs will differ from the homogeneous weights as in proposition 2. For non-homogeneous games that satisfy the conditions of proposition 1, expected payoffs will be linear in the minimum integer weights. For non-homogeneous games the conditions of proposition 2, expected payoffs will differ from the minimum integer weights as in proposition 2. We stress that these are only conjectures. However, as the table shows, they hold for all strong four-, five-, and six-player weighted voting games.

The right-hand side of the table shows how different the power indices are from the expected payoffs of the competitive bargaining game. In many cases the differences are slight, but in some cases they are quite large - see, for example, the five-player game with weights $(3,1,1,1,1)$, and the six-player game with weights $(4,1,1,1,1,1)$ and $(4,3,3,1,1,1)$. In all cases, the expected payoffs of the players with the largest weights are lower than their Shapley-Shubik and Banzhaf indices (except one case where they are the same). In all but

\footnotetext{
${ }^{11} \mathrm{~A}$ simple game is strong if the complement of a losing coalition is always winning-so, there are no blocking coalitions.

${ }^{12}$ The uniqueness proofs are case-by-case and repetitious so we omit them.
} 
one case, the expected payoffs of the players with the smallest weights are lower than their power indices.

\section{An Application: Council of Ministers of the EC (EU)}

The basic logic developed here has a wide range of applications. We consider here the weighted-voting scheme used for the Council of Ministers of the European Community, as that has been the subject of extensive debate.

The Council of Ministers of the European Community (now Union) uses a fixed-weight voting system. Each member country casts a single vote, but the votes have different weights, to compensate for differences in country size. Choice of weights has become increasingly controversial as the EC and now EU expands to include more countries. And, the EC and EU have been criticized for not being more attentive to the subtleties of power indices in weighted voting systems (e.g., Felsenthal and Machover, n.d.).

For simplicity of exposition we consider the weights under the original EC. In the original EC, the distribution of votes was France 4, Germany 4, Italy 4, Belgium 2, the Netherlands 2, and Luxembourg 1. Also, the Council uses Qualified Majority Voting. In the original EC, at least 12 of 17 votes were required to pass a measure.

Brams and Affuso (1985), Lane and Maeland (1995), Felsenthal and Machover (1997, n.d.), and others have calculated the power indices for the Council in each of these periods. The Banzhaf index resembles the other indices, so we discuss that measure here. The values of the Banzhaf index for France, Germany, and Italy in the original Council of Ministers are .238 each. The values for Belgium and the Netherlands are .143, and the value for Luxembourg is 0. Traditional power indices assign zero power to Luxembourg in the first period, because that country could never be pivotal in any minimum winning coalition. According to the Banzhaf index, Belgium and the Netherlands have power (.143) than their vote weights (.118) or than their minimum integer weights (.125).

The Baron-Ferejohn model predicts a nearly proportional pattern of expected payoffs to Council members. The expected payoffs are nearly proportional because in each case we reach a corner equilibrium. To calculate the expected values of the competitive bargaining payoffs, begin by describing minimum integer weights that characterize the game. The 
original weights are $(4,4,4,2,2,1)$, and the quota is 12 . The minimum integer weights are $(2,2,2,1,1,0)$, and corresponding quota is 6 . There are, then, three types of players - those with weight of 2 (call these A's), those with weight of 1 (B's) and those with weight 0 (C's).

The expected payoffs in this game are determined by two equations. First, the expected payoffs must sum to 1 . So, $3 V_{A}+2 V_{B}+V_{C}=1$. Let $V_{B}=\theta$. Then $V_{C}=1-8 \theta$. Second, the player with weight zero retains a certain amount of value if it is chosen. Because the type C player (Luxembourg) is a dummy player its integer weight is 0 . However, it still might be chosen as a proposer (with probability 1/6) and this proposal power gives it a positive expected payoff. If Luxembourg is chosen as proposer, it must include all three type A players or any two of the type A players and both type B players to have the necessary coalition size. In equilibrium, this player will pay the price of the 6 votes (i.e., $6 \theta$ ) and keep the remainder. As a result, the expected value for the type $\mathrm{C}$ player is $V_{C}=1-6 \theta$. Using these two equations, $\theta=5 / 42$, and expected payoffs may be calculated readily. ${ }^{13}$

The expected payoffs to the competitive bargaining game nearly equal the weights. The expected payoffs are $V_{A}=10 / 42=.238, V_{B}=5 / 42=.118$, and $V_{C}=1 / 21=.048$. The vote weights are .235, .118, and .059 for A, B, and C, respectively. Note that although the dummy player receives much more than its Banzhaf value of zero, it's expected payoff is its vote share in the original game.

Expansion of the EC in 1973 added the United Kingdom, Denmark and Ireland. The new system gave 10 votes each to France, Germany, Italy, and the UK; 5 votes each to Belgium and the Netherlands; 3 votes each to Denmark and Ireland; and 2 votes to Luxembourg. At least 41 of 58 votes were required to pass a measure. The values of the Banzhaf index were .167 for the countries with weight of $10 ; .091$ for the countries with weight of $5 ; .066$ for countries with weight of 3 ; and .016 for countries with weight of 2. Again Luxembourg seems to get short shrift. Luxembourg is no longer a "dummy," but it has a Banzhaf power measure of .016, with .034 share of the votes. By contrast, the competitive bargaining model has the following expected values: .170 for countries with weight of $10 ; .085$ for countries with weight of 5 ; .057 for countries with weight of 3 ; and .035 for countries with weight

\footnotetext{
${ }^{13}$ This does not establish uniqueness of the equilibrium expected payoffs. It is straightforward, however, to show that they are unique.
} 
of $2 .{ }^{14}$ It is worth noting that the competitive bargaining payoffs are nearly linear in the original voting weights. Also, the addition of other countries decreases each of the original member's expected payoff.

A non-cooperative bargaining model with an endogenous agenda, then, does not have the paradoxical flavor of other power indices. Luxembourg's Banzhaf value grows from nothing to .016, even though its share of the votes shrinks drastically from 1 out of 17 to 2 out of 58 . This might reflect the subtle nature of power, or it might reflect problems with the Banzhaf index, such as those noted by Holler $(1982,1987)$ and Garrett and Tsebelis (2001). The Baron-Ferejohn model apparently does not have this feature. Luxembourg's vote share fell and its power fell. It is ultimately an empirical matter whether this model better captures the essence of collective decision making in the EU.

\section{Discussion}

Our analysis differs from past efforts to analyze power in situations involving unequal numbers or weights of legislators votes. We have used a standard model of legislative bargaining due to Baron and Ferejohn to capture the "cost" of being a coalition member and have arrived at a proportional index. Conventional power indices are based on the notion that all combinations of coalition partners are equally likely. The intuition behind the proportional index. Any actor with $k$ votes has the same price or expected value in vote trading as $k$ actors with 1 vote each.

Ultimately, the value of the model rests on its empirical validity. Analyses of coalitions governments provide some validation for the linear result. Browne and Franklin (1973) and Browne and Frendreis (1980) find that the distribution of cabinet seats to parties is linear in the parties' seat shares, rather than non-linear, as predicted by power indices. Though not direct tests of the model developed here, these empirical findings are broadly consistent with our argument that the expected payoffs will typically be proportional to seat shares.

Further evidence for a fairly linear relationship between expected payoffs and voting weights comes from analyses of the distribution of economic benefits. A growing literature examines the association between the distribution of public expenditures across geographic

\footnotetext{
${ }^{14}$ The minimum integer weights are $(6,6,6,6,3,3,2,2,1)$, and the quota is 25 votes. These are the relevant weights for the analysis of the game, and the equilibrium is at a corner.
} 
and the political power or voting weight of the legislators representing those areas. Several studies note the linear pattern in these data (Bates and Lien 1985; Rodden 2001). Further work along these lines is needed.

The argument offered here, then, looks quite promising as a basis for further empirical and theoretical inquiry.

Obvious extensions of our analysis are to examine the non-cooperative coalition formation in variety of contexts. The model presented here can be generalized further and adapted to other decision-making situations. First, further analysis of competitive legislative bargaining should allow for different recognition rules and amendment procedures, especially open rules. Our intuition is that an open rule will act like a supermajority requirement $(\underline{w}>w / 2)$-it will lower proposal power, making corner equilibria less likely and the interior equilibrium is more likely. Second, the model can be applied to more complicated organizations, such legislatures with committees and to bicameral legislatures. Third, we hope to extend the analysis to allow actors to have more complicated preferences that include distribution of expenditures or positions and "spatial" policy. Strom, Budge, and Laver (1994), for example, look at modified Shapley values where constraints are placed on which coalitions can form due to insurmountable ideological differences.

Finally, this analysis bears directly on debate over the meaning and nature of power. Traditional power indices only reflect the influence that individuals have at the voting stage of the legislative process. Agenda-setting is another part of the process, however, and must be included in any complete analysis of legislative power. Incorporating proposal power changes the nature of power indices. In the case of the Baron and Ferejohn model, much of the non-linearity that has produced paradoxical results vanishes. The expected payoffs become more nearly linear in the vote shares, and even dummy players receive positive payoffs. 


\section{Appendix}

Proof of Proposition 1. (Existence) If $v_{t}=w_{t} / w$ for all $t$, then for each type $t, \underline{v}_{t}=$ $\left(\underline{w}-w_{t}\right) / w$. Substituting for $v_{t}$ and $\underline{v}_{t}$ in equation (1) and solving for $q_{t}$ then yields $q_{t}=$ $1-(w-\underline{w}) /\left((n-1) w_{t}\right)$. Clearly, $q_{t}$ is strictly increasing in $w_{t}$, and $q_{t}<1$ for all $t$. Also, since $w_{1}=1$, the assumption $w \leq \underline{w}+n-1$ implies that $q_{1} \geq 0$. So $q_{t} \in[0,1)$ for all $t$. Mixed proposal strategies for all players that sustain the equilibrium are as follows. Let $q_{t}$ be represented more generally as $q_{t}=\frac{1}{n-1}\left[\left(\sum_{i=1}^{T} \sum_{j=1}^{n_{i}} \rho_{i j t}\right)-1\right]$, where $\rho_{i j t}$ is the equilibrium probability that a legislator of type $t$ is included in a coalition formed by a proposer in bloc $j$ of type $i{ }^{15}$ Let $L_{t}$ be written $\left[\underline{I}_{t}, \bar{I}_{t}\right)$, where $\underline{I}_{t}=\sum_{i=1}^{t-1} n_{i}$ and $\bar{I}_{t}=\underline{I}_{t}+n_{t}$, and let $\gamma \sim U[0,1]$. Given $\rho_{i j t}$, if $i \neq t$ the proposer offers $v_{t}$ to the following members of $L_{t}$ :

$$
\begin{cases}{\left[\underline{I}_{t}+\gamma n_{t}, \underline{I}_{t}+\left(\gamma+\rho_{i j t}\right) n_{t}\right]} & \text { if } \gamma+\rho_{i j t}<1 \\ {\left[\underline{I}_{t}, 2 \underline{I}_{t}+\left(\gamma+\rho_{i j t}\right) n_{t}-\bar{I}_{t}\right] \cup\left[\underline{I}_{t}+\gamma n_{t}, \bar{I}_{t}\right)} & \text { otherwise. }\end{cases}
$$

The proposer offers 0 to all other members of type $t$. If $i=t$, then the proposer offers $v_{t}$ to legislators in $L_{t} \backslash L_{t j}$ in an identical fashion, and 0 to all other members of type $t$.

(Uniqueness) We now show that there is no equilibrium where $v_{t} \neq w_{t} / w$ for any type $t$. The relative cost of each type can be expressed as $v_{t} w / w_{t}$. If $v_{t} w / w_{t}>v_{r} w / w_{r}$, then type- $t$ players cost more per unit of voting weight than type- $r$ players, and are therefore strictly less desirable as coalition partners. Let $\theta=\min _{t}\left\{v_{t} w / w_{t}\right\} \leq 1$ be the relative price of the cheapest types, and let $\mathbf{T}_{C}=\left\{t \mid v_{t} w / w_{t}=\theta\right\}$ be the set of cheapest types, and let $\mathbf{T}_{E}=\left\{t \mid v_{t} w / w_{t}>\theta\right\}$ be the set of other (i.e., more expensive) types. We show that $\mathbf{T}_{E} \neq \emptyset$ leads to a contradiction.

First, note that $q_{t}<1$ for all $t \in \mathbf{T}_{C}$. To see this, let $\underline{v}=\min _{\{\mathbf{C} \mid \mathbf{C} \in \mathcal{W}\}} v(\mathbf{C})$ represent the cost of the least-costly winning coalitions. Then $\underline{v}_{t}=\underline{v}-v_{t}$ for all $t \in \mathbf{T}_{C}$ (since for any $t \in \mathbf{T}_{C}$, a type- $t$ proposer will build a coalition that costs exactly $\underline{v}$, including the proposer's own bloc). Equation (1) can then be written as $v_{t}=(1-\underline{v}) /\left((n-1)\left(1-q_{t}\right)\right)$. If $q_{t}=1$, then $v_{t}=\infty$, a contradiction.

Next, note that if $q_{t}<1$ for all $t \in \mathbf{T}_{C}$, then $w\left(\mathbf{T}_{C}\right)>\underline{w}-w_{T}$ (i.e., the set of legislators with types in $\mathbf{T}_{C}$ is decisive). Thus, proposers always choose all of their coalition partners

\footnotetext{
${ }^{15}$ This may be generalized further by allowing legislators within blocs to use different mixed strategies, but this will not be necessary.
} 
from $\mathbf{T}_{C}$, and $\underline{v}=\theta \underline{w} / w$.

Next, since proposers always buy minimal winning coalitions drawn from $\mathbf{T}_{C}$, for $t \in \mathbf{T}_{E}$, $q_{t}=0$ and $\underline{v}_{t}=\underline{v}-\theta w_{t} / w$. Substituting in equation (1) then yields:

$$
v_{t}=\frac{1}{n}-\frac{\theta \underline{w}}{n w}+\frac{\theta w_{t}}{n w} \text { for all } t \in \mathbf{T}_{E} .
$$

Also, as noted above,

$$
v_{t}=\frac{\theta w_{t}}{w} \text { for all } t \in \mathbf{T}_{C} .
$$

From equation (1), $v_{s}=\left(1-\underline{v}_{s}\right) / n$ for all types $s \in \mathbf{T}_{E}$. Also, $v_{t}$ is strictly increasing in $q_{t}$, so $v_{r}>\left(1-\underline{v}_{r}\right) / n$ for all $r \in \mathbf{T}_{C}$. Thus, $v_{r}=w_{r} \theta / w>v_{s}>w_{s} \theta / w$, and all types in $\mathbf{T}_{E}$ must have smaller voting weights than all types in $\mathbf{T}_{C}$. That is, there exists a cutoff type $t_{0}>1$ such that $\mathbf{T}_{E}=\left\{1, \ldots, t_{0}-1\right\}$ and $\mathbf{T}_{C}=\left\{t_{0}, \ldots, T\right\}$.

The sum of the continuation values must be 1 , so:

$$
\begin{aligned}
1 & =\sum_{t=1}^{T} n_{t} v_{t} \\
& =\sum_{t=1}^{t_{0}-1} n_{t}\left[\frac{1}{n}-\frac{\theta \underline{w}}{w n}+\frac{\theta w_{t}}{w n}\right]+\sum_{t=t_{0}}^{T} n_{t}\left[\frac{\theta w_{t}}{w}\right] \\
& =1-\frac{\theta \underline{w}}{w}+\left(\frac{\theta \underline{w}}{w n}-\frac{1}{n}\right) \sum_{t=t_{0}}^{T} n_{t}+\frac{\theta}{w n} \sum_{t=1}^{t_{0}-1} n_{t} w_{t}+\frac{\theta}{w} \sum_{t=t_{0}}^{T} n_{t} w_{t} \\
& =1-\frac{\theta \underline{w}}{w}+\left(\frac{\theta \underline{w}}{w n}-\frac{1}{n}\right) \sum_{t=t_{0}}^{T} n_{t}+\frac{\theta}{n}+\frac{\theta}{w}\left(1-\frac{1}{n}\right) \sum_{t=t_{0}}^{T} n_{t} w_{t} .
\end{aligned}
$$

Rewrite this as

$$
\frac{1}{n} \sum_{t=t_{0}}^{T} n_{t}=\theta\left[\frac{1}{n}-\frac{\underline{w}}{w}+\frac{\underline{w}}{w n} \sum_{t=t_{0}}^{T} n_{t}+\frac{1}{w}\left(1-\frac{1}{n}\right) \sum_{t=t_{0}}^{T} n_{t} w_{t}\right] .
$$

Using the fact that $\theta<1$ and rearranging then yields:

$$
\frac{1}{n}\left(1-\frac{\underline{w}}{w}\right) \sum_{t=t_{0}}^{T} n_{t}<\frac{1}{n}-\frac{\underline{w}}{w}+\frac{1}{w}\left(1-\frac{1}{n}\right) \sum_{t=t_{0}}^{T} n_{t} w_{t} .
$$

We now show that equation (3) cannot hold when $w \leq \underline{w}+n-1$. Define the function $\psi\left(t_{0}\right)$ by:

$$
\psi\left(t_{0}\right)=\frac{1}{n}-\frac{w}{w}+\frac{1}{w}\left(1-\frac{1}{n}\right) \sum_{t=t_{0}}^{T} n_{t} w_{t}-\frac{1}{n}\left(1-\frac{w}{w}\right) \sum_{t=t_{0}}^{T} n_{t}, \quad t_{0}=1,2, \ldots, T .
$$


Then equation (3) holds if and only if $\psi\left(t_{0}\right)>0$. Note that $\psi(1)=0$. Taking differences,

$$
\psi\left(t_{0}+1\right)-\psi\left(t_{0}\right)=n_{t_{0}}\left[\frac{1}{n}\left(1-\frac{\underline{w}}{w}\right)-\left(1-\frac{1}{n}\right) \frac{w_{t_{0}}}{w}\right] .
$$

When $t_{0}=1$, the term in square brackets is non-positive if $w \leq \underline{w}+n-1$. Also, the term in square brackets is decreasing in $t_{0}$ (since $w_{1}<w_{2}<\ldots<w_{T}$ ). So, if $w \leq \underline{w}+n-1$, then $\psi\left(t_{0}\right)$ is weakly decreasing in $t_{0}$, for all $t_{0} \geq 1$. Since $\psi(1)=0$, this implies that $\psi\left(t_{0}\right) \leq 0$ for all $t_{0}>1$.

Thus, at any equilibrium we must have $v_{t}=w_{t} / w$ for all $t$. So, the equilibrium is unique, up to differences in the probabilities of choosing different coalition partners that do not affect the players' expected payoffs. QED

Proof of Proposition 2. (i) First we show that there is no 'proportional' equilibrium; i.e., for some $t$ and constant $\eta, v_{t} \neq \eta w_{t} / w$. Note first that $\eta=1$; otherwise, $\sum_{t=1}^{T} n_{t} v_{t} \neq 1$. Suppose that $v_{t}=w_{t} / w$ for all $t$. Then $\underline{v}_{t}=\underline{w} / w-v_{t}=\left(\underline{w}-w_{t}\right) / w$, and by equation (1), $q_{t}=1-(w-\underline{w}) /\left((n-1) w_{t}\right)$. But since $w_{1}=1$, the assumption $w>\underline{w}+n-1$ implies that $q_{1}<0$ : contradicton.

Thus the relative prices of types must vary. As in the proof of Proposition 1 let $\theta=$ $\min _{t}\left\{v_{t} w / w_{t}\right\} \leq 1$ be the relative price of the cheapest types, and let $\mathbf{T}_{C}=\left\{t \mid v_{t} w / w_{t}=\theta\right\}$ be the set of cheapest types, and let $\mathbf{T}_{E}=\left\{t \mid v_{t} w / w_{t}>\theta\right\}$ be the set of other (i.e., more expensive) types.

We claim that $q_{r}<1$ for all $r \in \mathbf{T}_{C}$ and $q_{s}=0$ for all $s \in \mathbf{T}_{E}$. To see this, let $\underline{v}=\min _{\{\mathbf{C} \in \mathcal{W}\}} v(\mathbf{C})$. Then $\underline{v}_{r}=\underline{v}-v_{r}$ for all $r \in \mathbf{T}_{C}$. Equation (1) can then be written as $v_{r}=(1-\underline{v}) /\left((n-1)\left(1-q_{r}\right)\right)$. If $q_{r}=1$, then $v_{r}=\infty$, a contradiction. Next, note that if $q_{r}<1$ for all $r \in \mathbf{T}_{C}$, then $w\left(\mathbf{T}_{C}\right)>\underline{w}-w_{T}$ (i.e., the set of legislators with types in $\mathbf{T}_{C}$ is decisive). Thus, proposers always choose all of their coalition partners from $\mathbf{T}_{C}$. Thus, $\underline{v}=\theta \underline{w} / w$, and $q_{s}=0$ and $\underline{v}_{s}=\underline{v}-\theta w_{s} / w=\theta\left(\underline{w}-w_{s}\right) / w$ for all $s \in \mathbf{T}_{E}$.

Substituting into equation $(1), v_{s}=\left(1-\underline{v}_{s}\right) / n$ for all types $s \in \mathbf{T}_{E}$. Also, $v_{t}$ is strictly increasing in $q_{t}$, so $v_{r}>\left(1-\underline{v}_{r}\right) / n$ for all $r \in \mathbf{T}_{C}$. Thus, $v_{r}=w_{r} \theta / w>v_{s}>w_{s} \theta / w$, and all types in $\mathbf{T}_{E}$ must have smaller voting weights than all types in $\mathbf{T}_{C}$. That is, there exists a cutoff type $t_{0}>1$ such that $\mathbf{T}_{E}=\left\{1, \ldots, t_{0}-1\right\}$ and $\mathbf{T}_{C}=\left\{t_{0}, \ldots, T\right\}$.

Mixed proposal strategies for all players that sustain the equilibrium are as follows. Let 
$q_{t}$ be represented more generally as $q_{t}=\frac{1}{n-1}\left[\left(\sum_{i=1}^{T} \sum_{j=1}^{n_{i}} \rho_{i j t}\right)-1\right]$, where $\rho_{i j t}$ is the equilibrium probability that a legislator of type $t\left(t \in \mathbf{T}_{C}\right)$ is included in a coalition formed by a proposer in bloc $j$ of type $i$. Let $L_{t}$ be written $\left[\underline{I}_{t}, \bar{I}_{t}\right)$, where $\underline{I}_{t}=\sum_{i=1}^{t-1} n_{i}$ and $\bar{I}_{t}=\underline{I}_{t}+n_{t}$, and let $\gamma \sim U[0,1]$. Given $\rho_{i j t}$, if $i \neq t$ the proposer offers $v_{t}$ to the following members of $L_{t}$ :

$$
\begin{cases}{\left[\underline{I}_{t}+\gamma n_{t}, \underline{I}_{t}+\left(\gamma+\rho_{i j t}\right) n_{t}\right]} & \text { if } \gamma+\rho_{i j t}<1 \\ {\left[\underline{I}_{t}, 2 \underline{I}_{t}+\left(\gamma+\rho_{i j t}\right) n_{t}-\bar{I}_{t}\right] \cup\left[\underline{I}_{t}+\gamma n_{t}, \bar{I}_{t}\right)} & \text { otherwise. }\end{cases}
$$

The proposer offers 0 to all other members of type $t$. If $i=t$, then the proposer offers $v_{t}$ to legislators in $L_{t} \backslash L_{t j}$ in an identical fashion, and 0 to all other members of type $t$. QED

Proof of Remark. It is sufficient to show that for each type $t$ there exists an interior average recognition probability $q_{t}$ such that $v_{t}=w_{t} / w$. Adapting from (1),

$$
v_{t}=\frac{w_{t}}{w}\left(1-\underline{v}_{t}\right)+\frac{w-w_{t}}{w} q_{t} v_{t} .
$$

In any such equilibrium, $\underline{v}_{t}=\underline{w} / w-v_{t}$, and thus:

$$
\begin{gathered}
v_{t}=v_{t}\left(1-\frac{\underline{w}}{w}+\frac{w_{t}}{w}\right)+\frac{w-w_{t}}{w} q_{t} v_{t} . \\
q_{t}=\frac{\underline{w}-w_{t}}{w-w_{t}} .
\end{gathered}
$$

Since $w>\underline{w}>w_{t}, q_{t} \in(0,1)$.

Mixed proposal strategies satisfying $q_{t}$ are derived analogously to those in the proofs of Propositions 1 and 2. QED 


\section{References}

Banzhaf, John F., III. 1965. "Weighted Voting Doesn't Work: A Mathematical Analysis." Rutgers Law Review 19: 317-343.

Banzhaf, John F., III. 1968. "One Man 3.312 Votes: A Mathematical Analysis of the Electoral College." Villanova Law Review 13: 304-332.

Banks, Jeffrey S., and John Duggan. 2000. "A Bargaining Model of Collective Choice." American Political Science Review 94: 73-88.

Baron, David, and John Ferejohn. 1989. "Bargaining in Legislatures." American Political Science Review 83: 1181-1206.

Baron, David. 1991. "A Spatial Theory of Government Formation in Parliamentary System." American Political Science Review 85: 137-164.

Baron, David. 1996. "A Dynamic Theory of Collective Goods Programs." it American Political Science Review 90: 316-330.

Baron, David. 1998. "Comparative Dynamics of Parliamentary Governments." American Political Science Review 92: 593-609.

Baron, David, and Ehud Kalai. 1993. "The Simplest Equilibrium of a Majority-Rule Division Game." Journal of Economic Theory 61: 290-301.

Bates, Robert H., and Da-Hsiang Donald Lien. 1985. "On the Operations of the International Coffee Agreement." International Organization 39: 553-559.

Bennett, Elaine. 1983a. "The Aspiration Approach to Predicting Coalition Formation and Payoff Distributions in Sidepayment Games." International Journal of Game Theory 12: $1-28$.

Bennett, Elaine. 1983b. "Characterization Results for Aspirations in Games with Sidepayments." Journal of Mathematical Social Science 4: 229-241.

Binmore, Kenneth. 1987. "Perfect Equilibria in Bargaining Models." In The Economics of Bargaining, edited by Kenneth Binmore and Partha Dasgupta. Oxford: Basil Blackwell.

Brams, Steven J., and Paul J. Affuso. 1985. "New Paradoxes of Voting Power on the EC Council of Ministers." Electoral Studies 4: 135-139.

Browne, Eric C., and Mark N. Franklin. 1973. "Aspects of Coalition Payoffs in European Parliamentary Democracies." American Political Science Review 453-469.

Browne, Eric C., and John P. Frendreis. 1980. "Allocating Coalition Payoffs by Conventional Norm: An Assessment of the Evidence from Cabinet Coalition Situations." American Journal of Political Science 24: 753-768. 
Calvert, Randall, and Nathan Dietz. 1996. "Legislative Coalitions in a Bargaining Model with Externalities." Unpublished manuscript, University of Rochester.

Calvo, Emilio, and J. Javier Lasaga. 1997. "Probabilistic Graphs and Power Indices: An Application to the Spanish Parliament." Journal of Theoretical Politics 9: 477-501.

Chatterjee, Kalyan, Bhaskar Dutta, Debraj Ray, and Kunal Sengupta. 1993. "A Noncooperative Theory of Coalitional Bargaining." Review of Economic Studies 60: 463-478.

Diermeier, Daniel, and Timothy J. Feddersen. 1998. "Cohesion in Legislatures and the Vote of Confidence Procedure." American Political Science Review 92: 611-622.

Deegan, John, Jr. and Edward W. Packel. 1978. "A New Index of Power for Simple n-Person Games." International Journal of Game Theory 7: 113-123.

Dreyer, Jacob S., and Andrew Schotter. 1980. "Power Relationships in the International Monetary Fund: The Consequences of Quota Changes." Review of Economics and Statistics 62: 97-106.

Eraslan, Hulya. 2001. "Uniqueness of Asymmetric Equilibria in the Baron-Ferejohn Model." Journal of Economic Theory, forthcoming.

Felsenthal, Dan S. and Moshe Machover. 1997. "The Weighted Voting Rule in the EU's Council of Ministers, 1958-1995: Intentions and Outcomes." Electoral Studies 16: 3347.

Felsenthal, Dan S. and Moshe Machover. 1998. The Measurement of Voting Power: Theory and Practice, Problems and Paradoxes. Cheltenham: Edward Elgar.

Felsenthal, Dan S. and Moshe Machover. 2001. "Myths and Meanings of Voting Power." Journal of Theoretical Politics 13: 81-97.

Felsenthal, Dan S. and Moshe Machover. n.d. "Enlargement of the EU and Weighted Voting in its Council of Ministers." Unpublished manuscript, University of Haifa and Kings College, London.

Gamson, William A. 1961. "A Theory of Coalition Formation." American Sociological Review 3: 373-382.

Garrett, Geoffrey, and George Tsebelis. 1999a. "Why Resist the Temptation of Power Indices in the EU." Journal of Theoretical Politics 11: 291-308.

Garrett, Geoffrey, and George Tsebelis. 1999b. "More Reasons to Resist the Temptation of Power Indices in the EU." Journal of Theoretical Politics 11: 331-338.

Garrett, Geoffrey, and George Tsebelis. 2001. "Even More Reasons to Resist the Temptation of Power Indices in the EU." Journal of Theoretical Politics 13: 99-105.

Gul, Faruk. 1989. "Bargaining Foundations of Shapley Value." Econometrica 57: 81-95. 
Harrington, Joseph. 1989. "The Advantageous Nature of Risk Aversion in a Three-Player Bargaining Game Where Acceptance of a Proposal Requires a Simple Majority." Economics Letters 30: 195-200.

Harrington, Joseph. 1990a. "The Power of the Proposal Maker in a Model of Endogenous Agenda Formation." Public Choice 64: 1-20.

Harrington, Joseph. 1990b. "The Role of Risk Preferences in Bargaining When Acceptance of a Proposal Requires Less than Unanimous Approval." Journal of Risk and Uncertainty 3: 135-154.

Hart, Sergiu, and Andreu Mas Colell. 1996. "Bargaining and Value." Econometrica 64: $357-380$.

Holler, Manfred J. 1982. "Forming Coalitions and Measuring Power." Political Studies 30: 262-271.

Holler, Manfred J. 1987. "Paradox Proof Decision Rules in Weighted Voting." In The Logic of Multiparty Systems, edited by M.J. Holler. Dordrecht, The Netherlands: Martinus Nijhoff.

Holler, Manfred J. and Mika Widgren. 1999. "Why Power Indices for Assessing European Union Decision-Making?" Journal of Theoretical Politics 11: 321-330.

Hosli, Madeleine O. 1993. "Admission of European Free Trade Association States to the European Community: Effects on Voting Power in the European Community Council of Ministers. International Organization 47: 629-643.

Isbell, J.R. 1956. "A Class of Majority Games." Quarterly Journal of Math. Oxford 7: 183-187.

Johnston, R.J. 1978. "On the Measurement of Power: Some Reactions to Laver." Environment and Planning 10: 907-914.

Konig, Thomas, and Thomas Brauninger. 1996. "Power and Political Coordination in American and German Multi-Chamber Legislation." Journal of Theoretical Politics 8: 331-360.

Konig, Thomas, and Thomas Brauninger. 1998. "The Inclusiveness of European Decision Rules." Journal of Theoretical Politics 10: 125-142.

Lane, Jan-Erik and Reinert Maeland. 1995. "Voting Power Under the EU Constitution." Journal of Theoretical Politics 7: 223-230.

Lane, Jan-Erik, Reinert Maeland, and Sven Berg. 1995. "The EU Parliament: Seats, States and Political Parties." Journal of Theoretical Politics 7: 395-400.

Laurelle, Annick, and Mika Widgren. 1998. "Is the Allocation of Voting Power Among the EU States Fair?" Public Choice 94: 317-339. 
LeBlanc, William, James M. Snyder, Jr., and Micky Tripathi. 2000. "Majority-Rule Bargaining and the Under Provision of Public Investment Goods." Journal of Public Economics 75: 21-47.

Lucas, William F. 1978. "Measuring Power in Weighted Voting Systems." In Political and Related Models, edited by S.J. Brams, W.F. Lucas, and P.D. Straffin, Jr. New York: Springer-Verlag.

McCarty, Nolan M. 2000a. "Proposal Rights, Veto Rights, and Political Bargaining." American Journal of Political Science 44: 506-522.

McCarty, Nolan M. 2000b. "Presidential Pork: Executive Veto Power and Distributive Politics." American Political Science Review 94: 117-129.

McKelvey, Richard D., Peter C. Ordeshook, and Mark D. Winer. 1978. "The Competitive Solution for N-Person Games Without Transferable Utility, With an Application to Committee Games." American Political Science Review 72: 599-615.

Merrill, Samuel, III. 1978. "Citizen Voting Power Under the Electoral College: A Stochastic Model Based on State Voting Patterns." SIAM Journal on Applied Mathematics 34: 376-390.

Moldovanu, Benny, and Eyal Winter. 1995. "Order Independent Equilibria." Games and Economic Behavior 9: 21-34.

Norman, Peter. 2000. "Legislative Bargaining and Coalition Formation." SSRI Working Paper No. 2012.

Nurmi, Hannu, and Tommi Meskanen. 1999. "A Priori Power Measures and the Institutions of the European Union." European Journal of Political Research 35: 161-179.

Okada, Akira. 1996. "A Noncooperative Coalitional Bargaining Game with Random Proposers." Games and Economic Behavior 16: 97-108.

Owen, Guillermo. 1975. "Evaluation of a Presidential Election Game." American Political Science Review 69: 947-953.

Rabinowitz, George, and Stuart Elaine MacDonald. 1986. "The Power of the States in U.S. Presidential Elections." American Political Science Review 80: 65-87.

Rapoport, Amnon, and Esther Golan. 1985. "Assessment of Political Power in the Isreali Knesset." American Political Science Review 79: 673-692.

Riker, William H., and Lloyd S. Shapley. 1968. "Weighted Voting: Multinational Analysis for Instrumental Judgements." In J. Roland Pennock and John W. Chapman (eds.). Representation. New York: Atherton Press.

Rodden, Jonathan. 2001. "Strength in Numbers? Representation and Redistribution in the European Union." Unpublished manuscript, MIT. 
Schofield, Norman. 1976. "The Kernel and Payoffs in European Government Coalitions." Public Choice 26: 29-49.

Schofield, Norman. 1978. "Generalized Bargaining Sets for Cooperative Games." International Journal of Game Theory 7: 183-199.

Schofield, Norman. 1982. "Bargaining Set Theory and Stability in Coalition Governments." Journal of Mathematical Economics 7: 175-192.

Schofield, Norman. 1987. "Bargaining in Weighted Majority Voting Games." In The Logic of Multiparty Systems, edited by M.J. Holler. Dordrecht, The Netherlands: Martinus Nijhoff.

Selten, Reinhardt. 1981. "A Noncooperative Model of Characteristic Function Bargaining." In Essays in Game Theory and Mathematical Economics in Honor of Oskar Morgenstern, edited by Robert Aumann, John Harsanyi, Werner Hildebrand, Michael Muschler, M.A. Perls, Joachim Rosenmuller, Reinhardt Selten, Martin Shubik, and G.L. Thompson. Mannheim: Bibliographisches Institut.

Shapley Lloyd S. 1953. "A Value for n-Person Games." In Contributions to the Theory of Games (Annals of Mathematical Studies 28), edited by H.W. Kuhn and A.W. Tucker. Princeton, NJ: Princeton University Press.

Shapley Lloyd S., and Martin Shubik. 1954. "A Method for Evaluating the Distribution of Power in a Committee System." American Political Science Review 48: 787-792.

Steuneberg, Bernard, Dieter Schmidtchen, and Christian Koboldt. 1999. "Strategic Power in the European Union: Evaluating the Distribution of Power in Policy Games. Journal of Theoretical Politics 11: 339-366.

Strom, Kaare, Ian Budge, and Michael J. Laver. 1994. "Constraints on Cabinet Formation in Parliamentary Democracies." American Journal of Political Science 38: 303-335.

Sutter, Matthias. 2000a. "Fair Allocation and Re-Weighting of Votes and Voting Power in the EU Before and After the Next Enlargement." Journal of Theoretical Politics 12: 433-449.

Sutter, Matthias. 2000b. "Flexible Integration, EMU, and Relative Voting Power in the EU." Public Choice 104: 41-62.

Tsebelis, George, and Geoffrey Garrett. 2000. "Agenda Setting Power, Power Indices and Decision Making in the European Union." International Review of Law and Economics 16: $345-362$.

Teasdale, Anthony L. 1996. "The Politics of Majority Voting in Europe." Political Quarterly 67: 101-115.

Widgren, Mika. 1994. "Voting Power in the EC Decision-Making and the Consequences of Two Different Enlargements." European Economic Review 38: 1153-1170. 
Widgren, Mika. 2000. "A Note on Matthias Sutter." Journal of Theoretical Politics 12: 451-454.

Winter, Eyal. 1996. "Voting and Vetoing." American Political Science Review 90: 813-823. 


\begin{tabular}{|c|c|c|c|c|c|c|c|c|c|c|c|c|}
\hline \multicolumn{13}{|c|}{$\begin{array}{l}\text { Table } 1 \\
\text { es vs. Expected Payoffs }\end{array}$} \\
\hline $\begin{array}{l}\text { Voting } \\
\text { Weights }\end{array}$ & \multicolumn{6}{|c|}{ Power Indices \& Expected Payoffs } & \multicolumn{6}{|c|}{$\begin{array}{c}\text { Power Indices Relative to } \\
\text { to Expected Payoffs }\end{array}$} \\
\hline \multirow[t]{3}{*}{$2,1,1,1$} & .500 & .167 & .167 & .167 & & & 1.25 & 0.84 & 0.84 & 0.84 & & \\
\hline & .500 & .167 & .167 & .167 & & & 1.25 & 0.84 & 0.84 & 0.84 & & \\
\hline & .400 & .200 & .200 & .200 & & & & & & & & \\
\hline \multirow[t]{3}{*}{$3,1,1,1,1$} & .600 & .100 & .100 & .100 & .100 & & 1.40 & 0.70 & 0.70 & 0.70 & 0.70 & \\
\hline & .636 & .091 & .091 & .091 & .091 & & 1.48 & 0.64 & 0.64 & 0.64 & 0.64 & \\
\hline & .429 & .143 & .143 & .143 & .143 & & & & & & & \\
\hline \multirow[t]{3}{*}{$2,2,1,1,1$} & .300 & .300 & .133 & .133 & .133 & & 1.05 & 1.05 & 0.93 & 0.93 & 0.93 & \\
\hline & .286 & .286 & .143 & .143 & .143 & & 1.00 & 1.00 & 1.00 & 1.00 & 1.00 & \\
\hline & .286 & .286 & .143 & .143 & .143 & & & & & & & \\
\hline \multirow[t]{3}{*}{$3,2,2,1,1$} & .400 & .233 & .233 & .067 & .067 & & 1.20 & 1.05 & 1.05 & 0.60 & 0.60 & \\
\hline & .385 & .231 & .231 & .077 & .077 & & 1.16 & 1.04 & 1.04 & 0.69 & 0.69 & \\
\hline & .333 & .222 & .222 & .111 & .111 & & & & & & & \\
\hline \multirow[t]{3}{*}{$2,1,1,1,1,1$} & .333 & .133 & .133 & .133 & .133 & .133 & 1.17 & 0.93 & 0.93 & 0.93 & 0.93 & 0.93 \\
\hline & .333 & .133 & .133 & .133 & .133 & .133 & 1.17 & 0.93 & 0.93 & 0.93 & 0.93 & 0.93 \\
\hline & .286 & .143 & .143 & .143 & .143 & .143 & & & & & & \\
\hline \multirow[t]{3}{*}{$4,1,1,1,1,1$} & .666 & .067 & .067 & .067 & .067 & .067 & 1.50 & 0.60 & 0.60 & 0.60 & 0.60 & 0.60 \\
\hline & .750 & .050 & .050 & .050 & .050 & .050 & 1.69 & 0.45 & 0.45 & 0.45 & 0.45 & 0.45 \\
\hline & .444 & .111 & .111 & .111 & .111 & .111 & & & & & & \\
\hline \multirow[t]{3}{*}{$3,2,1,1,1,1$} & .400 & .200 & .100 & .100 & .100 & .100 & 1.20 & 0.90 & 0.90 & 0.90 & 0.90 & 0.90 \\
\hline & .393 & .179 & .107 & .107 & .107 & .107 & 1.18 & 0.81 & 0.96 & 0.96 & 0.96 & 0.96 \\
\hline & .333 & .222 & .111 & .111 & .111 & .111 & & & & & & \\
\hline \multirow[t]{3}{*}{$2,2,2,1,1,1^{a}$} & .233 & .233 & .233 & .100 & .100 & .100 & 1.05 & 1.05 & 1.05 & 0.90 & 0.90 & 0.90 \\
\hline & .233 & .233 & .233 & .100 & .100 & .100 & 1.05 & 1.05 & 1.05 & 0.90 & 0.90 & 0.90 \\
\hline & .222 & .222 & .222 & .111 & .111 & .111 & & & & & & \\
\hline \multirow[t]{3}{*}{$3,3,2,1,1,1$} & .300 & .300 & .200 & .067 & .067 & .067 & 1.10 & 1.10 & 1.10 & 0.74 & 0.74 & 0.74 \\
\hline & .286 & .286 & .214 & .071 & .071 & .071 & 1.05 & 1.05 & 1.18 & 0.78 & 0.78 & 0.78 \\
\hline & .273 & .273 & .182 & .091 & .091 & .091 & & & & & & \\
\hline
\end{tabular}

For each weighted voting game, the first line gives Shapley-Shubik indices, second line gives Banzhaf indices, and third line gives the expected payoffs from equilibrium of legislative bargaining game.

${ }^{a}=$ non-homogeneous game

${ }^{b}=$ corner-solution in legislative bargaining game 


\begin{tabular}{|c|c|c|c|c|c|c|c|c|c|c|c|c|}
\hline \multicolumn{13}{|c|}{ Table 1 (continued) } \\
\hline \multirow{2}{*}{$\begin{array}{l}\text { Voting } \\
\text { Weights } \\
4,2,2,1,1,1\end{array}$} & \multicolumn{6}{|c|}{ Power Indices \& Expected Payoffs } & \multicolumn{6}{|c|}{$\begin{array}{l}\text { Power Indices Relative to } \\
\text { to Expected Payoffs }\end{array}$} \\
\hline & .467 & .167 & .167 & .067 & .067 & .067 & 1.71 & 0.92 & 0.92 & 0.74 & 0.74 & 0.74 \\
\hline & .462 & .154 & .154 & .077 & .077 & .077 & 1.69 & 0.85 & 0.85 & 0.85 & 0.85 & 0.85 \\
\hline & .364 & .182 & .182 & .091 & .091 & .091 & & & & & & \\
\hline \multirow[t]{3}{*}{$3,2,2,2,1,1^{a}$} & .300 & .167 & .167 & .167 & .100 & .100 & 1.10 & 0.92 & 0.92 & 0.92 & 1.10 & 1.10 \\
\hline & .300 & .167 & .167 & .167 & .100 & .100 & 1.10 & 0.92 & 0.92 & 0.92 & 1.10 & 1.10 \\
\hline & .273 & .182 & .182 & .182 & .091 & .091 & & & & & & \\
\hline \multirow[t]{3}{*}{$4,3,3,1,1,1^{b}$} & .367 & .267 & .267 & .033 & .033 & .033 & 1.47 & 1.07 & 1.07 & 0.40 & 0.40 & 0.40 \\
\hline & .346 & .269 & .269 & .039 & .039 & .039 & 1.38 & 1.08 & 1.08 & 0.40 & 0.40 & 0.40 \\
\hline & .250 & .250 & .250 & .083 & .083 & .083 & & & & & & \\
\hline \multirow[t]{3}{*}{$3,3,2,2,2,1^{a b}$} & .234 & .234 & .167 & .167 & .167 & .033 & 1.03 & 1.03 & 1.10 & 1.10 & 1.10 & 0.36 \\
\hline & .234 & .234 & .167 & .167 & .167 & .033 & 1.03 & 1.03 & 1.10 & 1.10 & 1.10 & 0.36 \\
\hline & .227 & .227 & .152 & .152 & .152 & .091 & & & & & & \\
\hline \multirow[t]{3}{*}{$4,3,2,2,1,1^{a b}$} & .368 & .231 & .134 & .134 & .067 & .067 & . & . & . & . & . & . \\
\hline & .357 & .214 & .143 & .143 & .071 & .071 & . & . & . & . & . & . \\
\hline & $\cdot$ & $\cdot$ & $\cdot$ & $\cdot$ & $\cdot$ & $\cdot$ & & & & & & \\
\hline \multirow[t]{3}{*}{$5,2,2,2,1,1^{a b}$} & .533 & .133 & .133 & .133 & .033 & .033 & . & . & . & . & . & . \\
\hline & .542 & .125 & .125 & .125 & .042 & .042 & . & . & . & . & . & . \\
\hline & $\cdot$ & $\cdot$ & $\cdot$ & $\cdot$ & . & . & & & & & & \\
\hline
\end{tabular}

For each weighted voting game, the first line gives Shapley-Shubik indices, second line gives Banzhaf indices, and third line gives the expected payoffs from equilibrium of legislative bargaining game.

${ }^{a}=$ non-homogeneous game

${ }^{b}=$ corner-solution in legislative bargaining game 